\title{
Qualidade sensorial, nutricional e microbiológica do pão enriquecido com casca de
}

\author{
OVo \\ Sensorial, nutritional and microbiological quality bread enriched eggshell \\ Calidad sensorial, nutricional y microbiológica del pan enriquecido con cáscara de huevo
}

Recebido: 02/08/2021 | Revisado: 05/08/2021 | Aceito: 16/08/2021 | Publicado: 20/08/2021

\author{
Adriene Ribeiro Lima \\ ORCID: https://orcid.org/0000-0003-2653-066X \\ Universidade Federal Fluminense, Brasil \\ E-mail: adrienelima@id.uff.br \\ Juliana Cristina Costa \\ ORCID: https://orcid.org/0000-0003-1036-1777 \\ Centro Universitário UNA, Brasil \\ E-mail: julianacristina442@hotmail.com \\ Maria Marta Amancio Amorim \\ ORCID: https://orcid.org/0000-0001-8268-2508 \\ Universidade Aberta de Lisboa, Portugal \\ E-mail: martamorim@hotmail.com \\ Ieda Trindade Rocha \\ ORCID: https://orcid.org/0000-0003-1099-1592 \\ Centro Universitário UNA, Brasil \\ E-mail: ieda_t_rocha@ hotmail.com \\ Rejane Cássia Faria \\ ORCID: https://orcid.org/0000-0001-5682-8358 \\ Centro Universitário UNA, Brasil \\ E-mail: rejanecassiafaria@yahoo.com.br \\ Jade Francisco da Silva \\ ORCID: https://orcid.org/0000-0002-1411-1874 \\ Centro Universitário UNA, Brasil \\ E-mail: jadysilver@outlook.com \\ Daniela Almeida do Amaral \\ ORCID: https://orcid.org/0000-0002-7451-4157 \\ Universidade Federal de Ouro Preto, Brasil \\ E-mail: dan.amaral@gmail.com \\ Eric Liberato Gregório \\ ORCID: https://orcid.org/0000-0002-1420-6275 \\ Centro Universitário UNA, Brasil \\ E-mail: liberato.eric@gmail.com \\ Fernanda Meneghello Delvivo \\ ORCID: https://orcid.org/0000-0002-7678-6121 \\ Centro Universitário UNA, Brasil \\ E-mail: fernandadelvivo@prof.una.br \\ Nayara Mussi Monteze \\ ORCID: https://orcid.org/0000-0003-3534-1262 \\ Centro Universitário UNA, Brasil \\ E-mail: nayara.monteze@prof.una.br
}

\begin{abstract}
Resumo
O objetivo deste estudo é elaborar um pão caseiro adicionado de farinha de casca de ovo e avaliar a sua qualidade sensorial, nutricional e microbiológica. Foram elaboradas três formulações de pães contendo batata inglesa, óleo de soja, ovos, açúcar cristal, leite de coco verde, farinha de casca de ovo, fermento biológico seco, noz moscada, sal e proporções diferentes de farinha de trigo tradicional e integral. O projeto foi aprovado pelo comitê de ética e pesquisa do Centro Universitário Una de Belo Horizonte. Realizaram-se os testes de aceitabilidade utilizando a escala hedônica e de intenção de compra e de consumo. As análises bromatológicas de proteína, gordura, fibra, cálcio, sódio, umidade e cinzas para elaboração da informação nutricional contendo valor energético, carboidratos, proteínas, gorduras totais, gorduras saturadas, gorduras trans, fibra alimentar, cálcio e sódio foram realizados na amostra de melhor aceitabilidade. Realizaram-se análises microbiológicas de Estafilococos coagulase positiva, Bacillus cereus presuntivo, bolores e leveduras, Escherichia coli e Salmonella spp. A avaliação global das formulações F1, F2 e F3 para os atributos

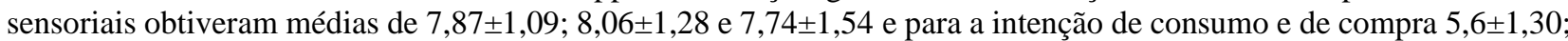
$5,74 \pm 1,67$ e 5,48 $\pm 1,73$, respectivamente. O pão se apresentou como um alimento fonte de fibras, baixo teor de sódio e
\end{abstract}


dentro dos padrões microbiológicos para consumo. Concluiu-se que, o pão caseiro adicionado de farinha de casca de ovo isento de lactose obteve ótima aceitação entre os avaliadores e mostrou-se um produto com grande potencial de mercado.

Palavras-chave: Panificação; Análise sensorial; Análise bromatológica; Análise microbiológica; Informação nutricional.

\begin{abstract}
This study aims to prepare a homemade bread added with eggshell flour and evaluate its sensory, nutritional, and microbiological quality. Three bread formulations were prepared to contain potato, soy oil, eggs, crystal sugar, green coconut milk, eggshell flour, dry biological yeast, nutmeg and salt, and different proportions of traditional and whole wheat flour. The project was approved by the Ethics and Research Committee of Centro Universitário Una de Belo Horizonte. The acceptability test was carried out using the hedonic scale and the purchase and consumption intention tests. The bromatological analysis of protein, fat, fiber, calcium, sodium, moisture and ash for the preparation of nutritional information containing energy value, carbohydrates, proteins, total fats, saturated fats, trans fats, dietary fiber, calcium, and sodium were carried out in the sample. better acceptability. Microbiological analyzes of coagulasepositive Staphylococci, presumptive Bacillus cereus, yeasts and molds, Escherichia coli, and Salmonella spp. The global evaluation of the formulations F1, F2, and F3 for the sensory attributes had averages of 7.87 $\pm 1.09 ; 8.06 \pm 1.28$, and $7.74 \pm 1.54$ and for the intention to consume and purchase $5.6 \pm 1.30 ; 5.74 \pm 1.67$ and $5.48 \pm 1.73$, respectively. The bread was presented as a food source of fiber, low in sodium, and within the microbiological standards for consumption. It was concluded that the homemade bread added with lactose-free eggshell flour obtained great acceptance among the evaluators and proved to be a product with great market potential.
\end{abstract}

Keywords: Bakery; Sensory analysis; Chemical analysis; Microbiological analysis; Nutritional information.

\title{
Resumen
}

El objetivo de este estudio es elaborar un pan casero con harina de cáscara de huevo y evaluar su calidad sensorial, nutricional y microbiológica. Se prepararon tres formulaciones de pan que contenían papa, aceite de soja, huevos, azúcar cristal, leche de coco verde, harina de cáscara de huevo, levadura biológica seca, nuez moscada y sal y diferentes proporciones de harina de trigo tradicional e integral. El proyecto fue aprobado por el Comité de Ética e Investigación del Centro Universitário Una de Belo Horizonte. La prueba de aceptabilidad se realizó mediante la escala hedónica y las pruebas de intención de compra y consumo. En la muestra mejor aceptabilidad. Los análisis microbiológicos de estafilococos coagulasa positivos, presunto Bacillus cereus, mohos y levaduras, Escherichia coli y Salmonella spp. La evaluación global de las formulaciones F1, F2 y F3 para los atributos sensoriales tuvo promedios de $7.87 \pm 1.09 ; 8.06$ \pm 1.28 y $7.74 \pm 1.54$ y por la intención de consumir y comprar $5.6 \pm 1.30 ; 5,74 \pm 1,67$ y 5,48 $\pm 1,73$, respectivamente. El pan se presentó como fuente alimentaria de fibra, bajo en sodio y dentro de los estándares microbiológicos de consumo. Se concluyó que el pan casero adicionado con harina de cáscara de huevo sin lactosa obtuvo gran aceptación entre los evaluadores y resultó ser un producto con gran potencial de mercado.

Palabras clave: Panadería; Análisis sensorial; Análisis químico; Análisis microbiológico; Información nutricional.

\section{Introdução}

Os pães são consumidos mundialmente e na alimentação saudável estão na base da pirâmide alimentar brasileira, como uma das principais fontes de carboidratos da dieta (Philippi, Latterza \& Ribeiro, 1999). Eles são elaborados, em sua maioria, a partir de farinha refinada proveniente do endosperma do trigo, rico em amido e, portanto, considerados fonte de energia e de nutrientes para o ser humano (Borges et al., 2011).

Alguns estudos têm sido desenvolvidos com o propósito de melhorar o valor nutritivo de pães por meio da utilização de farinhas integrais com adição de macronutrientes e micronutrientes, o que tem atraído a atenção dos consumidores, por complementarem as necessidades nutricionais diárias ou por conterem substâncias com alegações de propriedades funcionais (Borges et al., 2011). Desde que a adição de outras farinhas não ocasione prejuízo à qualidade do produto, o uso de farinha mista, ou seja, farinha de trigo branca com farinha de trigo integral, pode ser recomendável para substituir em parte a farinha de trigo branca largamente utilizada, a fim de agregar ao produto maior valor nutricional (Deodato, 2015).

Farinhas provenientes de diferentes grãos, sementes, cascas e hortaliças têm sido amplamente utilizadas em pães devido aos seus benefícios à saúde, que além das fibras alimentares, os produtos elaborados com estas farinhas podem fornecer ainda 
vitaminas, proteínas, minerais, carboidratos, o que contribuem para a redução do risco de várias doenças, como câncer, diabetes, obesidades e doenças cardiovasculares (Deodato, 2015).

A farinha de casca de ovo é utilizada em preparações visando combater a desnutrição, contribuir para o crescimento e o fortalecimento completo dos ossos e dos dentes, auxiliar a coagulação do sangue e a contração muscular (Feijó, Campos, \& Vizeu, 2005; Naves et al., 2007; Pereira et al., 2008). É importante ressaltar que a única fonte disponível de cálcio para o organismo humano é obtida da dieta (Bueno \& Czepieleskki, 2008).

As organizações não governamentais têm utilizado a farinha da casca de ovo como fonte de cálcio de baixo custo, o que a torna um ingrediente adequado para ser adicionado em pães para suprir as necessidades de cálcio do organismo (Prado et al., 2007), visto que 7,2 milhões de toneladas de cascas de ovos são descartadas por ano no mundo, nos processamentos tecnológicos (Dallacorte, Behling \& Quadros, 2017).

A casca de ovo de galinha possui $94 \%$ de carbonato de cálcio, sendo $40 \%$ biodisponível, $1 \%$ de fosfato de cálcio, $1 \%$ de carbonato de magnésio, 4\% de proteína e água (Neves, 1998; Vieira et al., 2017).

Diante do exposto, este estudo tem como objetivo elaborar um pão caseiro adicionado de farinha de casca de ovo e avaliar a sua qualidade sensorial, nutricional e microbiológica.

\section{Metodologia}

Trata-se de um estudo experimental conduzido no Laboratório de Técnica Dietética do Centro Universitário Una, Belo Horizonte, Brasil aprovado pelo Comitê de Ética em Pesquisa desse centro universitário, sob o protocolo número 1.109.928. Os participantes da análise sensorial assinaram o Termo de Consentimento Livre e Esclarecido (TCLE).

\subsection{Formulação dos pães}

A formulação dos pães foi estabelecida por meio de testes preliminares, a fim de se avaliar a proporção ideal de cada ingrediente. Foram elaborados três tipos de pães: pão com farinha de trigo tradicional (Formulação 1 - F1), pão com farinha de trigo tradicional e farinha de trigo integral na proporção 1/1 (Formulação 2 - F2 padrão) e pão com farinha de trigo integral (Formulação 3 - F3). Os ingredientes - farinha de trigo tradicional, farinha de trigo integral, batata inglesa, óleo de soja, ovos, açúcar cristal, leite de coco verde, farinha de casca de ovo, fermento biológico seco, noz moscada e sal com os respectivos percentuais utilizados nas três formulações dos pães podem ser verificados na Tabela 1. 
Tabela 1. Ingredientes das três formulações dos pães adicionados de farinha de casca de ovo.

\begin{tabular}{|c|c|c|c|}
\hline \multirow{2}{*}{ Ingredientes } & \multicolumn{3}{|c|}{ Formulações* } \\
\hline & F1 & F2 & F3 \\
\hline Farinha de trigo tradicional $(\%)$ & 53,5 & 26,8 & 0 \\
\hline Farinha de trigo integral $(\%)$ & 0 & 26,8 & 53,5 \\
\hline Batata inglesa descascada $(\%)$ & 12,9 & 12,9 & 12,9 \\
\hline Óleo de soja refinado $(\%)$ & 12,9 & 12,9 & 12,9 \\
\hline Ovo branco de galinha sem casca $(\%)$ & 10,8 & 10,8 & 10,8 \\
\hline Açúcar cristal $(\%)$ & 6,4 & 6,4 & 6,4 \\
\hline Leite de coco verde in natura $(\%)$ & 1,7 & 1,7 & 1,7 \\
\hline Farinha de casca de ovo $(\%)$ & 1,1 & 1,1 & 1,1 \\
\hline Fermento biológico seco instantâneo (\%) & 0,5 & 0,5 & 0,5 \\
\hline Noz moscada em pó $(\%)$ & 0,1 & 0,1 & 0,1 \\
\hline Sal $(\%)$ & 0,1 & 0,1 & 0,1 \\
\hline
\end{tabular}

*F1= teste (pão com farinha de trigo tradicional); F2= padrão (pão com farinha de trigo tradicional e farinha de trigo integral na proporção $1 / 1) ; \mathrm{F} 3=$ teste (pão com farinha de trigo integral).

Fonte: os autores (2021).

A farinha da casca do ovo e o leite de coco verde foram preparados seguindo as técnicas descritas a seguir.

\subsection{Preparo da farinha da casca de ovo}

Para o preparo da farinha da casca de ovo foram utilizadas 20 cascas de ovos brancos de galinha de granja armazenadas no congelador de geladeira, seguindo a técnica descrita por Silva Júnior (2005): lavagem em água corrente, imersão em solução de hipoclorito de sódio a 200 ppm por 10 minutos, fervura durante 10 minutos; secagem em forno convencional a gás à $80{ }^{\circ} \mathrm{C}$ por 2 horas, com mistura a cada intervalo de 20 minutos, trituração no liquidificador e peneiração com retirada das películas, obtendo-se o pó da casca.

\subsection{Preparo do leite de coco in natura a partir do coco verde}

O leite de coco utilizado na formulação dos pães foi preparado seguindo os passos: lavagem do coco, imersão em solução clorada a 200 ppm, enxague, retirada da água do coco, corte do coco em 2 partes, retirada da polpa, trituração da polpa e água de coco no liquidificador por aproximadamente 5 minutos até obter uma consistência homogênea.

\subsection{Preparo do pão}

No pré-preparo das três formulações de pães, a batata inglesa foi lavada, descascada e cortada à brunoise, os ovos foram lavados um a um, com a retirada da casca. Esses ingredientes e os demais foram pesados na balança digital Glam ${ }^{\circledR}$, modelo GL301, de carga máxima de 5 kg e graduação de 1 grama, a fim de se obter o peso líquido. A batata foi cozida e as três formulações de pão foram preparadas manualmente, seguindo as técnicas descritas por Suas (2012) e as normas de boas práticas de fabricação da Resolução da Diretoria Colegiada (RDC) número 216 de 12 de setembro de 2004 (Brasil, 2004). Os pães foram assados no forno a $180^{\circ} \mathrm{C}$ e após resfriamento foi conduzida a análise sensorial.

\subsection{Análise sensorial}

A análise sensorial foi realizada por meio do teste afetivo com 50 avaliadores não treinados, que assinaram o TCLE, de ambos os sexos, com idade média de 26 anos, sendo professores, estudantes e funcionários do Centro Universitário Una. Os 
avaliadores receberam amostras das três formulações oferecidas em embalagens descartáveis para realização do teste de aceitabilidade utilizando a escala hedônica, ancorada em seus extremos pelos termos "gostei muitíssimo" (9) e "desgostei muitíssimo" (1), a fim de se avaliar os atributos aroma, sabor, aparência/cor e textura/consistência (Sidel \& Stone, 1993). Para a intenção de consumo e de compra foram utilizadas escalas de sete pontos segundo Chaves (1980). Nesse teste o participante expressa seu desejo em consumir e comprar o produto degustado.

\subsection{Análise bromatológica e informação nutricional da amostra F2}

A F2 padrão - farinha trigo tradicional e farinha de trigo integral na proporção 1/1 apresentou boa aceitação sensorial e foi enviada ao laboratório Hidrocepe, localizado em Belo Horizonte, para a realização das análises bromatológicas das proteínas, gorduras, fibras, cálcio e sódio, cinzas e umidade.

Para a quantificação de proteínas utilizou-se o Método de Kjeldahl das Normas Analíticas do Instituto Adolfo Lutz (IAL, 2005), para a gordura total e a saturada, as normas do Laboratório Nacional de Referência Animal - LANARA (Brasil, 1981). O método utilizado para quantificar umidade, cinzas, sódio, cálcio e fibra alimentar foi o preconizado pela Association of Official Analitical Chemists (AOAC, 2005). Os carboidratos totais foram determinados pelo cálculo da diferença entre $100 \mathrm{~g}$ do alimento e a soma total dos valores encontrados para umidade, proteínas, lipídios e cinzas (AOAC, 2005), de acordo com a Equação ( $\mathrm{E}=\%$ de carboidrato)

$$
\mathrm{E}=100-(\% \text { umidade }+\% \text { cinzas }+\% \text { proteínas }+\% \text { lipídios })
$$

A elaboração da informação nutricional com os nutrientes obrigatórios - valor energético, carboidratos, proteínas, gorduras totais, gorduras saturadas, gorduras trans, fibra alimentar, cálcio e sódio foi baseada nas resoluções da Agência Nacional de Vigilância (ANVISA), que regulamentam a rotulagem dos alimentos (Brasil, 2003a; Brasil, 2003b; Brasil, 2012; Brasil, 2015). Conforme estabelece a RDC número 359 de 2003 quanto às porções dos alimentos embalados, o pão caseiro adicionado de farinha de casca de ovo elaborado pertence ao grupo de alimentos "produtos de panificação", sua porção é de $50 \mathrm{~g}$ o que corresponde a medida caseira de uma unidade (Brasil, 2003a).

\subsection{Análise microbiológica}

A análise microbiológica foi realizada na amostra F2 pelo Laboratório de Microbiologia de Alimentos do Instituto de Ciências Biológicas e da Saúde do Centro Universitário Una, Belo Horizonte.

Os parâmetros analisados foram contagem de Estafilococos coagulase positiva, Bacillus cereus presuntivo e bolores e leveduras, cujos resultados foram expressos em unidades formadoras de colônias por grama (UFC/g), contagem de Escherichia coli, cujos resultados foram expressos em Número Mais Provável por grama (NMP/g) e pesquisa de Salmonella spp. em 25 gramas. As análises foram realizadas segundo o Compendium of Methods for the Microbiological Examination of Food American Public Health Association (APHA, 2001).

Os resultados obtidos foram comparados aos valores preconizados pela RDC número 331 de 2019 e a Instrução Normativa (IN) número 60 de 2019 que regulamentam os padrões microbiológicos para alimentos (Brasil, 2019a; Brasil 2019b).

\section{Resultados e Discussão}

\subsection{Análise sensorial}

O pão que obteve a melhor avaliação sensorial foi a amostra F2 composto de farinhas de trigo tradicional e integral, batata inglesa, óleo de soja, açúcar, leite de coco verde, farinha de casca de ovo, fermento biológico, noz moscada e sal. Esse 
pão difere da amostra F1, composta pela farinha de trigo tradicional e da amostra F3, pela farinha de trigo integral. Os demais ingredientes e percentuais são os mesmos nas três amostras.

Os resultados da análise sensorial dos pães, por escala de nove pontos, demonstraram que as notas médias dos atributos aroma, sabor, cor e textura variaram entre 7,67 e 8,14, para as formulações F1, F2 e F3, sendo superiores em todos os atributos na amostra F2. O atributo maior pontuado da amostra F2 foi a cor $(90,4 \%)$, seguido da textura $(90 \%)$, sabor $(89,11 \%)$ e aroma $(88,8 \%)$. Na avaliação global a F2 obtive maior média, seguida da F1 e da F3, conforme ilustrado na Tabela 2, sendo superior $(6,7$ e 7,3) aos pães elaborados por Oliveira et al (2011) e Gurgel et al. (2011), respectivamente.

A avaliação global nas formulações 1, 2 e 3 demonstrou que a adição da farinha da casca do ovo e de dois tipos de farinhas, tradicional e/ou integral, não influenciaram na aceitação sensorial dos pães. O grande desafio no desenvolvimento de produtos alimentícios é a obtenção de uma formulação com aspectos nutricionais atrativos, mas também com características sensoriais diferenciadas, de modo a atender as expectativas do consumidor (Sebrae, 2008).

Tabela 2. Avaliação dos atributos sensoriais por escala hedônica das formulações 1,2 e 3.

\begin{tabular}{cccc}
\hline \multirow{2}{*}{ Atributo } & Média \pm DP & Média \pm DP & \multicolumn{1}{c}{ Média \pm DP } \\
\cline { 2 - 4 } & F1 $^{*}$ & F2 $^{*}$ & $7,740 \pm 1,643$ \\
\hline Aroma & $7,760 \pm 1,138$ & $7,990 \pm 1,367$ & $7,670 \pm 1,724$ \\
\hline Sabor & $7,770 \pm 1,278$ & $8,020 \pm 1,456$ & $7,880 \pm 1,486$ \\
\hline Cor & $8,070 \pm 1,166$ & $8,140 \pm 1,198$ & $7,680 \pm 1,711$ \\
\hline Textura & $7,900 \pm 1,150$ & $8,090 \pm 1,429$ & $7,743 \pm 1,539$ \\
\hline Avaliação global & $7,875 \pm 1,089$ & $8,060 \pm 1,278$ & (3) \\
\hline
\end{tabular}

* F1 (formulação 1 - teste): pão com farinha de trigo tradicional; F2 (formulação 2 - padrão): pão com farinha trigo tradicional e farinha de trigo integral na proporção 1/1; F3 (formulação 3 - teste): pão com farinha de trigo integral

Fonte: os autores (2021).

As notas dos atributos aroma $(7,99)$, sabor $(8,02)$ e textura $(8,09)$ do pão elaborado com farinhas de trigo tradicional e integral, batata inglesa, óleo de soja, açúcar, leite de coco verde, $1 \%$ de farinha de casca de ovo, fermento biológico, noz moscada e sal foram superiores ao pão preparado por Oliveira et al. (2011) com farinha de trigo, gordura, açúcar, linhaça e 2,3\% de farinha de casca de ovo: 7,1, 6,8 e 6,4, respectivamente. As notas do pão preparado por Gurgel et al. (2011) composto por farinha de trigo, gordura vegetal hidrogenada, açúcar, soro de leite, $2,3 \%$ de pó de casca de ovo receberam notas inferiores $(6,8,7,4,7)$, respectivamente ao presente estudo.

A intenção de consumo e de compra variou de 5,48 - 78,28\% a 5,78-82,57\% (Tabela 3), sendo maiores na amostra F2. As médias das notas de intenção de consumo e de compra foram similares na amostra F2. As notas da intenção de consumo foram maiores do que as notas da intenção de compra. Para que um produto seja classificado como aceito em seus atributos sensoriais, deve obter o índice de aceitabilidade mínimo de 70\%, segundo Teixeira (2009).

Tabela 3. Avaliação da intenção de compra e de consumo das formulações 1, 2 e 3.

\begin{tabular}{lccc}
\hline & Média \pm DP & Média \pm DP & Média \pm DP \\
\cline { 2 - 4 } & Formulação 1* & Formulação 2* & Formulação 3* \\
\hline Intenção de consumo & $5,700 \pm 1,291$ & $5,780 \pm 1,624$ & $5,510 \pm 1,720$ \\
\hline Intenção de compra & $5,600 \pm 1,303$ & $5,740 \pm 1,673$ & $5,480 \pm 1,732$ \\
\hline
\end{tabular}

* F1 (formulação 1 - teste): pão com farinha de trigo tradicional; F2 (formulação 2 - padrão): pão com farinha trigo tradicional e farinha de trigo integral na proporção $1 / 1 ; \mathrm{F} 3$ (formulação 3 - teste): pão com farinha de trigo integral

Fonte: os autores (2021). 


\subsection{Análise nutricional}

Os resultados da composição centesimal da amostra F2 - proteína, gordura total, gordura saturada, fibra alimentar total, cálcio, sódio, cinzas e umidade serviram de base para a construção da informação nutricional do pão caseiro adicionado de farinha de casca de ovo. Na tabela 4 é apresentada a informação nutricional de $50 \mathrm{~g}$ da formulação F2, com referência no valor diário (VD) baseado numa dieta de $2000 \mathrm{kcal}$.

Na apuração do valor energético do pão aplicou-se os fatores de Atwater para proteínas, carboidratos e gorduras (FAO, 2003). O valor energético do pão equivaleu a 1,5 porção, considerando a porção recomendada de 150 kcal, do grupo cereais, tubérculos e raízes da pirâmide adaptada à população brasileira (Philippi, Latterza \& Ribeiro, 1999).

Os carboidratos foram calculados por diferença e representam o maior percentual dentre os macronutrientes, 64,20\% em relação ao valor energético. As proteínas de origem vegetal e animal equivalem a 7,31\% em relação ao valor energético. O pão adicionado de farinha de casca de ovo desenvolvido pode ser sugerido como alternativa dietética ou como coadjuvante no tratamento dietoterápico de indivíduos com intolerância à lactose e alergia à proteína do leite de vaca, já que o produto não apresenta leite de vaca na sua composição, pois o mesmo foi substituído por leite de coco in natura.

As gorduras representam 28,49\% em relação ao valor energético, sendo que gordura saturada representa 33,80\% das gorduras totais e não possui gordura trans, calculada segundo dados tabelados por Unicamp (2011).

Tabela 4. Informação nutricional da formulação F2.

\begin{tabular}{lcc}
\hline & $\begin{array}{c}\text { INFORMAÇÃO NUTRICIONAL } \\
\text { Porção 50 g (1 unidade) }\end{array}$ & \% VD (*) \\
\hline Valor energético & Quantidade por porção & $11 \%$ \\
\hline Carboidratos & $224 \mathrm{kcal}=941 \mathrm{~kJ}$ & $13 \%$ \\
\hline Proteínas & $36 \mathrm{~g}$ & $5 \%$ \\
\hline Gorduras totais & $4,1 \mathrm{~g}$ & $13 \%$ \\
\hline Gorduras saturadas & $7,1 \mathrm{~g}$ & $11 \%$ \\
\hline Gorduras trans & $2,4 \mathrm{~g}$ & $* *$ \\
\hline Fibra alimentar & $0 \mathrm{~g}$ & $12 \%$ \\
\hline Cálcio & $2,9 \mathrm{~g}$ & $5 \%$ \\
\hline Sódio & $45 \mathrm{mg}$ & $1 \%$ \\
\hline
\end{tabular}

Seus valores diários podem ser maiores ou menores dependendo de suas necessidades energéticas

* Valores diários de referência com base numa dieta de $2000 \mathrm{Kcal}$ ou 8400 kJ.

Fonte: os autores (2021).

O pão F2 é um alimento fonte de fibras, pois apresentou $3 \mathrm{~g}$ e o mínimo recomendado seria 2,5 gramas por porção, segundo a RDC número 54 de 12 de novembro de 2012 (Brasil, 2012). As fibras quando consumidas na quantidade adequada provocam o retardo do esvaziamento gástrico, reduzem os níveis da glicemia e insulina após sua ingestão, auxiliam na redução do peso corporal e atuam na melhoria do sistema imunológico (Bernaud \& Rodrigues, 2013).

Sabe-se que a farinha da casca do ovo branco é riquíssima em cálcio, $39.900 \mathrm{mg}, 37.400 \mathrm{mg}, 37.400 \mathrm{mg}$ e $30263,72 \mathrm{mg}$ em $100 \mathrm{~g}$ de farinha de casca, dados obtidos por Peres \& Waszczynskyj (2010), Naves et al. (2007a), Milbradt et al. (2015) e Villar, Saabaa-Srur \& Marques (2010), respectivamente. Já Lima et al. (2020) encontraram valores superiores na farinha de casca de ovos fabricada com ovos caipiras, $51.100 \mathrm{mg}$ em $100 \mathrm{~g}$ da amostra.

No presente estudo não foi analisado o teor de cálcio da farinha de casca de ovos, somente do pão F2, que apresentou $45 \mathrm{mg}$ de cálcio, representando 5\% em relação ao VDR, devido à adição de 1,1\% de farinha de casca de ovo. Lima et al (2020) também utilizaram $1 \%$ da farinha da casca de ovo caipira e encontraram valores bem superiores ao do presente estudo, 90 mg em $50 \mathrm{~g}$ do beiju, 140,66 mg em $50 \mathrm{~g}$ de bolo de farinha de trigo e valores inferiores, no preparo de $50 \mathrm{~g}$ de cuscuz de milho, 
6,86 mg. Naves et al. (2007a) elaboram bolo simples, bolo de fubá e biscoito de polvilho enriquecidos com 1\% do pó da casca de ovo (37,4\% de cálcio) e o teores de cálcio foram $197 \mathrm{mg}, 114 \mathrm{mg}$ e $214 \mathrm{mg}$ por $50 \mathrm{~g}$ de produto.

A F2 apresentou-se um alimento com muito baixo teor de sódio quando comparado à pães tradicionais já comercializados. Quanto ao sódio, o mesmo se enquadra nas condições "máximo de $40 \mathrm{mg}$ de sódio" recebendo o atributo de "muito baixo teor de sódio" (33 mg).

No caso de rotulagem obrigatória dos principais alimentos que causam alergia alimentar, a RDC número 26 de 2015 (Brasil, 2015) estabelece e dispõe os requisitos básicos para apresentar as informações que se fazem necessárias para complementar a amostra F2, aplicando em conjunto com a RDC número 259 de 2002 (Brasil, 2002), que aprova o regulamento técnico para rotulagem de produtos embalados e suas atualizações. O produto em questão apresentará as seguintes informações: Alérgicos: contém derivado de trigo, ovo e pode conter soja, centeio, cevada e aveia. contém glúten.

\subsection{Análise microbiológica}

A IN número 60 de 2019 determina limites para produtos de panificação como pães estáveis à temperatura ambiente. A amostra F2 de pão caseiro adicionado de farinha de casca de ovo apresentou-se dentro dos padrões microbiológicos estabelecidos pela legislação vigente (Brasil, 2019a; Brasil 2019b) conforme mostra a Tabela 5.

Tabela 5. Análise microbiológica da formulação 2

\begin{tabular}{ccc}
\hline Micro-organismos & $\begin{array}{c}\text { Pão caseiro adicionado de } \\
\text { farinha de casca de ovo isento } \\
\text { de lactose }\end{array}$ & $\begin{array}{c}\text { Referência: IN n } \\
\mathbf{2 0 1 9} \text { } 60 \text { de }\end{array}$ \\
\hline E.coli $(\mathrm{NMP} / \mathrm{g})^{*}$ & $<3,0$ & $10^{2}$ \\
\hline Estafilococos coagulase positiva (UFC/g)** & $5,0 \times 10^{2}$ & $5,0 \times 10^{2}$ \\
\hline Bacillus cereus presuntivo (UFC/g) & $<1,0 \times 10^{2}$ & $10^{3}$ \\
\hline Bolores e leveduras (UFC/g) & $<1,0 \times 10^{2}$ & $10^{4}$ \\
\hline Salmonella spp. / $25 \mathrm{~g}$ & Ausência & Ausência \\
\hline
\end{tabular}

* NMP/g - número mais provável por grama; ** UFC/g - unidades formadoras de colônias por grama

*** TPAI - tolerância para amostra indicativa.

Fonte: os autores (2021)

Neste estudo, a adição da farinha de casca de ovo ao pão se mostrou segura do ponto de vista microbiológico, assim como no estudo de Lima et al. (2020). Esses autores avaliaram a qualidade microbiológica do pó da casca de ovos caipiras aeróbios mesófilos, coliformes termotolerantes, coliformes totais, Staphylococcus spp., Salmonella spp. e todas as análises apresentaram resultados satisfatórios. De modo igual na avaliação microbiológica de cascas de ovos de granja e caipira conduzida por Milbradt et al. (2015) as contagens de Staphylococcus coagulase positiva, coliformes totais e termotolerantes e pesquisa de Salmonella spp. apresentaram-se dentro dos padrões microbiológicos estabelecido para ovos. Naves et al. (2007b) também obtiveram resultados satisfatórios, sem risco biológico, nas amostras de pó da casca de ovo destinadas a comunidades carentes analisadas quanto à contagem de bolores e leveduras, aeróbios mesófilos, coliformes totais e termotolerantes e, não houve contaminação por bactérias patogênicas (Salmonella spp.) e potencialmente patogênicas (Staphylococcus aureus e Bacillus cereus).

\section{Conclusão}

A adição de farinha de casca de ovo não influenciou na aceitação dos pães. As características sensoriais do pão caseiro adicionado de farinha de casca de ovo e isento de lactose teve ótima aceitação e mostrou-se um produto com grande potencial 
de mercado, enquadrando-se também nos padrões aceitáveis de qualidade higiênico-sanitária e microbiológicos. Além disso, é um pão fonte de fibras, apresenta baixo teor de sódio e quantidade significativa de cálcio.

A casca de ovo de galinha é totalmente desprezada nos restaurantes durante o preparo das refeições e pelas indústrias nos processos de fabricação de maioneses e ovos pasteurizados ou em pó. Nesse sentido, mais estudos sobre o aproveitamento desses resíduos devem ser realizados, variando quantidades de farinha e avaliando suas características em pães e outros produtos alimentícios, assim como a avaliação da biodisponibilidade do cálcio nos produtos alimentícios produzidos com a adição dessa farinha.

\section{Referências}

AOAC (2005). Association of Official Analytical Chemists. Official methods of analysis of Association of Official Analytical Chemists International. 17 ed. Washington.

APHA (2001). American Public Health Association. Compendium of methods for the microbiological examination of foods. 4. ed. Washington: APHA.

Bernaud, F. S. R., Rodrigues, T. C. (2013). Fibra alimentar - Ingestão adequada e efeitos sobre a saúde do metabolismo. Arq Bras Endocrinol Metab., 57(6), 397-405. https://doi.org/10.1590/S0004-27302013000600001

Brasil (1981). Ministério da Agricultura e Pecuária. MAPA. Portaria no 001 de 07/10/81. Diário Oficial. Brasília, DF

Brasil (2003a). Ministério da Saúde. Agência Nacional de Vigilância Sanitária. ANVISA. Resolução - RDC Nº 359 , de 23 de dezembro de 2003. Aprova o Regulamento Técnico de Porções de Alimentos Embalados para fins de Rotulagem Nutricional. Diário Oficial. Brasília, DF.

Brasil (2003b). Ministério da Saúde. Agência Nacional de Vigilância Sanitária. ANVISA. Resolução - RDC nº 360 , de 23 de dezembro de 2003 . Aprova o Regulamento da Rotulagem Nutricional Obrigatória, Diário Oficial. Brasília, DF.

Brasil (2004). Ministério da Saúde. Agência Nacional de Vigilância Sanitária. ANVISA. Resolução - RDC No 216 de 12 de setembro de 2004 . Aprova o Regulamento Técnico de Boas Práticas Para Serviços de Alimentação, Diário Oficial. Brasília, DF.

Brasil (2012). Ministério da Saúde. Agência Nacional de Vigilância Sanitária. ANVISA. Resolução - RDC No 54, de 12 de novembro de 2012. Aprova o Regulamento Técnico de Sobre Informação Nutricional Complementar. Diário Oficial. Brasília, DF.

Brasil (2015). Ministério da Saúde. Agência Nacional de Vigilância Sanitária. ANVISA. Resolução - RDC N²6, de 02 de julho de 2015 . Aprova o Regulamento Técnico Sobre Rotulagem Obrigatória dos Principais Alimentos que Causam Alergias Alimentares, Diário Oficial. Brasília, DF.

Brasil (2019a). Ministério da Saúde. Agência Nacional de Vigilância Sanitária. ANVISA. Resolução RDC nº 331 de 23 de dezembro de 2019 . Dispõe sobre os padrões microbiológicos de alimentos e sua aplicação. Diário Oficial. Brasília, DF.

Brasil (2019b). Ministério da Saúde. Agência Nacional de Vigilância Sanitária. ANVISA. Instrução Normativa n 60 , de 23 de dezembro de 2019 . Estabelece as listas de padrões microbiológicos para alimentos. Diário Oficial. Brasília, DF.

Borges, J. T. S., Pirozi, M.R., Paula, C.D., Ramos, D.L., \& Chaves, J.B.P. (2011). Caracterização físico-química e sensorial de pão de sal enriquecido com farinha integral de linhaça. B. CEPPA, 29(1), 83-96. Disponível em https://revistas.ufpr.br/alimentos/article/viewFile/22758/16540. Acesso em: 19 mai. 2021.

Bueno, A. L., \& Czepielewski, M. A. (2008). The importance for growth of dietary intake of calcium and vitamin D. Jornal de Pediatria, 84(5), 386-394. https://doi.org/10.2223/JPED.1816

Chaves, J. B. P. (1980). Avaliação sensorial de alimentos: métodos de análises. Viçosa: Editora da Universidade Federal de Viçosa, 1980.

Dallacorte, C., Behling, S.M., \& Quadros, C. S. (2017). Implantação de uma indústria de farinha de casca de ovo: um estudo da viabilidade econômica. Revista Tecnológica, 6(1)M, 83-103. Disponível em: https://uceff.edu.br/revista/index.php/revista/article/view/236. Acesso em: 19 mai. 2021.

Deodato, J. N. V. (2015). Produção e avaliação microbiológica, físico-química e toxicológica de farinha de Pilosocereus chrysostele e sua utilização como aditivo na formulação de broa preta. Dissertação apresentada ao Programa de Pós-Graduação em Sistemas Agroindustriais da Universidade Federal de Campina Grande, UFCG, como parte dos requisitos necessários para obtenção do título de Mestre em Sistemas Agroindustriais com ênfase em Ciência e Tecnologia de Alimentos. UFCG: Pombal - PB. Disponível em: https://1library.org/document/zwkj687z-producao-avaliacao-microbiologica-toxicologicapilosocereus-chrysostele-utilizacao-formulacao.html. Acesso em: 19 mai. 2021.

FAO (2003). Food and Agriculture Organization. Food energy - methods of analysis and conversion factors. Disponível em: <http://www.fao.org/3/y5022e/y5022e04.htm\#bm4.2>. Acesso em: 19 mai. 2021.

Feijó, M. B. S., Campos, R. C., \& Vizeu, V. E. (2005). Determinação da composição mineral de diferentes formulações de multimistura. Ciência e Tecnologia de Alimentos, 25(2), 254-258. https://doi.org/10.1590/S0101-20612005000200012

Gurgel, C. S. S., Maciel, J.F., Farias, L.R.G., Costa, M.J.C., \& Moreira, T.M. (2011). Aceitação e intenção de consumo de pão de forma enriquecido com soro de leite em pó e carbonato de cálcio. Rev Inst Adolfo Lutz, 70(3), 283-289. Disponível em:

https://periodicos.saude.sp.gov.br/index.php/RIAL/article/view/32534/31365. Acesso em: 19 mai. 2021. 
IAL (2005). Instituto Adolfo Lutz. Métodos físicos para análise de alimentos. $4^{\mathrm{a}}$ ed. $1^{\mathrm{a}}$ ed. São Paulo: Instituto Adolfo Lutz. Disponível em https://bibliodigital.unijui.edu.br:8443/xmlui/bitstream/handle/123456789/5939/M\%c3\%a9todos\%20f\%c3\%adsicoqu\%c3\%admicos\%20para\%20an\%c3\%a1lise\%20de\%20alimentos.pdf?sequence=1\&isAllowed=ygital. Acesso em: 19 mai. 2021.

Lima, A. A. O., França, D. V. C., Bergamp, L., \& Marinho, V. I. S. (2017). Análise sensorial de pão sem glúten e sem caseína elaborado a partir de farinha de arroz e leite de coco. Rev. Uningá, 32(1), 183-194. Disponível em https://1library.org/document/qod8k0jz-analise-sensorial-gluten-caseina-elaborado-partirfarinha-leite.html. Acesso em: 19 mai. 2021

Lima, N. P., Brito, D. A.P., Lima, L. S., Soares, S. C. P., Pacheco, B. S. (2020). Uso do pó da casca de ovos caipiras como fonte de cálcio em produtos alimentícios. Acta Tecnológica, 15 (2), 113-129. http://dx.doi.org/10.35818/acta.v15i2.946

MilbradtI, B. G., Müller, A. L. H., Silva, J. S., Lunardi, J. R. L., Milani, I. G., Flores, É. M. M., Callegaro, M. G. K., \& Emanuelli, T. (2015). Casca de ovo como fonte de cálcio para humanos: composição mineral e análise microbiológica. Ciência Rural, 45(3), 560-566. http://dx.doi.org/10.1590/0103$8478 \mathrm{cr} 20140532$

Naves, M. M. V., Fernandes, D. C., Prado, C. M. M., \& Teixeira, L. S. M. (2007a). Fortificação de alimentos com o pó da casca de ovo como fonte de cálcio. Food Sci. Technol, 27 (1), 99-103. https://doi.org/10.1590/S0101-20612007000100017

Naves, M. M. V., Prado, C. M. M., Fernandes, D. C., \& Serafini, Á. B. (2007b). Avaliação microbiológica do pó da casca de ovo e otimização da técnica de elaboração do produto. Pesq Agropec Trop 37(2): 113-118. Disponível em https://www.revistas.ufg.br/pat/article/view/1836/1748. Acesso em: 19 mai. 2021.

Neves, M. A. (1998). Alternativas para valorização da casca de ovo como complemento alimentar e em implantes ósseos. Dissertação (Mestrado em Ciência dos Alimentos). Departamento de Ciência e Tecnologia de Alimentos. Universidade Federal de Santa Catarina, Florianópolis, Brasil. Disponível em https://repositorio.ufsc.br/handle/123456789/111226. Acesso em: 19 mai. 2021.

Oliveira, M. A., Ferreira, C. R., Júnior, S. R., \& Saraiva, S. H. (2011). Desenvolvimento de uma formulação de pão suplementado com cálcio. enciclopédia biosfera, Centro Científico Conhecer, 7 (13), 1419-1426.

http://www.conhecer.org.br/enciclop/2011b/ciencias\%20da\%20saude/desenvolvimento\%20de\%20uma\%20formulacao\%20de\%20pao.pdf. Acesso em: 19 mai. 2021.

Prado, C.M.M., Fernandes, D. C., Teixeira, L.S.M., \& Naves, M. M. V. (2007). Fortificação de alimentos com o pó da casca de ovo como fonte de cálcio. Ciênc. Tecnol. Aliment., 27(1), 99-103. Disponível em https://www.scielo.br/j/cta/a/VC4X9GJNkwJV7HGnCVw7fFc/?format=pdf. Acesso em: 19 mai. 2021.

Pereira, G. A. P. et al. (2009). Cálcio dietético - estratégias para otimizar o consumo. (2009). Revista Brasileira de Reumatologia, 49 (2), 64-80. https://doi.org/10.1590/S0482-50042009000200008

Peres, A. P., Waszczynsky, J. (2010). Farinha de casca de ovo: determinação do teor de cálcio biodisponível. Visão Acadêmica, 11(1), 74-80. http://dx.doi.org/10.5380/acd.v.11i1.21357.

Philippi, S.T., Latterza, A. R., Cruz, A \& T.R., \& Ribeiro, L.C (1999). Pirâmide alimentar adaptada: guia para escolha dos alimentos. Rev. Nutr. 12 (1), 65-80. https://doi.org/10.1590/S1415-52731999000100006

Sebrae. (2008). Serviço Brasileiro de Apoio às Micro e Pequenas Empresas. Pães caseiros não industrializados. Estudos de mercado SEBRAE/ESPM. Disponível em: <https://www.academia.edu/4675984/p\%C3\%A3es_caseiros_n\%C3\%A3o_industrializados>. Acesso em: 28 jun. 2021.

Sidel, J. L., \& Stone, H. (1993). Sensory evaluation: practices. $2^{\text {a }}$ ed. London: Academic Press.

Silva Junior, E. A. (2005). Manual de controle higiênico-sanitário em serviços de alimentação. 6. ed. São Paulo: Varela.

Suas, M. (2012). Panificação e Viennoiserie: abordagem profissional. $1^{\text {a }}$ ed. São Paulo: Cengage Learning.

Teixeira, L. V. (2009). Análise Sensorial da Indústria de Alimentos. Revista do Instituto de Laticínios Cândido Tostes, 366(64): 12-21. Disponível em https://www.revistadoilct.com.br/rilct/article/view/70/76. Acesso em: 28 jun. 2021

Unicamp. Universidade Estadual de Campinas. (2011). Tabela Brasileira de Composição de Alimentos. TACO. $4^{\mathrm{a}}$ ed. Campinas: Unicamp; 2011.

Vieira, L. A. F., Pinho, M. D., Pinheiro, I. P., \& Silva, N. S. (2017). Obtenção de óxido de cálcio a partir da casca de ovo de galinha. The Journal of Engineering and Exact Sciences, 3(8), 1159-1166. https;//doi.org. /10.18540/jcecvl3iss8pp1159-1166

Vilar, J. S., Sabaa-Srur, A. U. O., \& Marques, R. G. (2010). Composição química da casca de ovo de galinha em pó. B. CEPPA, 28 (2), 247-254. Disponível em: https://revistas.ufpr.br/alimentos/article/view/20439/13698. Acesso em: 28 jun. 2021. 